\title{
Theoritical Perspective of Knowledge Management as Part of Human Capital Management: Proposed Quantitative Framework
}

\author{
Fazluz ZAMAN ${ }^{1}$, Nehal MAHTAB ${ }^{2} \&$ Syed Jafar Raza RIZVI ${ }^{3}$ \\ ${ }^{I}$ Business Trainer and Curriculum Writer, University of Wollongong College (UOWC), Australia and \\ Academies Australasia, Group of Colleges \\ ${ }^{2}$ Lecturer, Faculty of Business \& Law Leeds Metropolitan University, Leeds, United Kingdom \\ ${ }^{3}$ Research Officer, Center for Equity and Health Systems, The International Centre for Diarrhoeal Disease \\ Research, Bangladesh (icddr,b)
}

\begin{abstract}
Managers must analyze the training needs and provide proper leadership, division of tasks and responsibilities, remuneration systems, and performance appraisal to facilitate KM and hence to contribute to overall organizations' HRM. People management should be the integral part of corporate strategy and a key responsibility for all managers. Managers must recruit, retain and motivate people with proper compensation packages. At the same time an environment of trust must be created so that people freely share their knowledge. While recruiting, one thing must be kept in mind that people comes from diverse backgrounds, so manages must be very careful in honoring the values, cultures and sub-cultures of all the diverse backgrounds. Further, they should gain the faith of the employees that they are working for a caring and trustworthy organization. Without equity and fairness tacit knowledge cannot be shared. However, mangers can do delayering of jobs, employee empowerment and promote team culture to successfully share tacit knowledge. Therefore, creating and valuating important information that helps to fulfill the organizational objectives. Knowledge management is the proper mixture of implicit and explicit in an organization to outperform and thus, enhance the customer value and can result as a major boost in the company's performance.
\end{abstract}

Keywords: Human Resource Management, Human Resource Life Cycle, Human Capital Management, Knowledge Management and Strategic Alignment

\section{Objectives Of The Study}

Knowledge Management (KM) refers to the processes or tools an organization uses to collect, analyze, store, and distribute its intellectual capital. Here we have discussed the knowledge management and the implication of knowledge management in Human resource management. Before the discussion,

Firstly, we have examined the Knowledge management related issues, KM strategies, and then, the Human resource related issues and strategies that they follow.

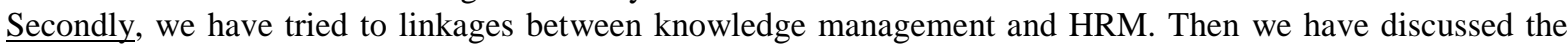
importance of knowledge management in HRM.

\section{SCOPE}

Researchers and academics have taken different perspectives on knowledge management ranging from technological solutions to the use of best practices. It has been the subject of much discussion over the past decade. It resides in human minds. Employee training and motivation are the key factors to knowledge management. Though there are widespread arguments among scholars about the definition of KM, it has been applied to a very broad spectrum of activities designed to manage, exchange and create or enhance intellectual assets within an organization. The paper takes a comprehensive view on knowledge management and show the importance in HRM.

\section{Sample}

\section{Proposed Quantitative Methodology}

A questionnaire survey in possible industries in different sector is most appropriate for this kind of study. The sample will be obtained by using the stratified methodology. The strata will be different industrial sector including organizations. Using personal connection-samplers, the questionnaires will be taken personally to most organizations.

To evaluate the possible variable are

* Employee skills

* Employee attitudes

* Employee behavior 
Cost reduction, customer service, distribution channels.

Effectiveness, efficiency development of an organization.

Management style, organization culture to see contingencies of an organization

Age of organization, size of organization.

\title{
Statistical Analysis
}

To test the raised research question of the proposed frame-work, the methodology of structural equation models (SEM) or latent variable models (LVM) will be used, via the maximum likelihood estimation (MLE).

Structural equation modeling (SEM) is a statistical technique for testing and estimating causal relations using a combination of statistical data and qualitative causal assumptions. This definition of SEM was articulated by the geneticist Sewall Wright (1921), the economist Trygve Havelmo (1943) and the cognitive scientist Herbert A. Simon (1953), and formally defined by Judea Pearl (2000) using a calculus of counterfactuals. Structural equation models (SME) allow both confirmatory and exploratory modeling, meaning they are suited to both theory testing and theory development.

\begin{abstract}
A latent variable model (LVM) is a statistical model that relates a set of variables (so-called manifest variables) to a set of latent variables. Different types of the latent variable model can be grouped according to whether the manifest and latent variables are categorical or continuous.

We will assess the overall model fit following Bollen's recommendation to examine multiple indices. We will employ the chi-square and normed-chi-square tests, the goodness of fit index (GFI), and examining the root mean squares error approximation (RMSEA). The goodness-of-fit indexes confirmed the validity of the operational model. Furthermore, the normed fit index (NFI) and comparative fit index (CFI) will be also used, for investigating the structure that best fit the empirical data. To incorporate these methods, at first we will check the mean, standard deviation and inter-correlations (Univariate analysis/Descriptive Statistics). Then we will check the bivariate correlations which indicate the basic relationships depicted in the hypotheses that accompany the model.
\end{abstract}

\section{LIMITATIONS}

Our greatest challenge in this report was to integrate knowledge management with Human Resource Management. However there were very few limitations that we came across. Firstly it is very difficult to define HRM since it's a very general and broad concept. It is the integration of different functions that it has which is why it was hard to define it. Then again knowledge management is also a broad concept so coming up with the relationship between KM and HRM was a bit difficult. Besides, the problem also existed in finding the books on "Knowledge Management."

\section{KNOWLEDGE MANAGEMENT: WHAT IT IS?}

Knowledge management is a combination of core skills and competencies in information as well as in human resource management. It is increasingly recognized as a key organizational asset. The causes organization success are competitive advantage, customer focus, improve employee relation and development, innovation, lower cost at the same time it refers to the ability of an organization to develop novel and useful ideas and solution (Marakas 1999, pg 440) (Bhatt, 2001 \& Chourides, Longbottom \& Murphy, 2003).

KM provides a broad basis for understanding the issues, technologies, theories, applications, opportunities, and challenges being faced by researchers and organizations today in their mission for knowledge management. It is a strategy of getting the right knowledge to the right people at the right time $\left(\mathrm{O}^{\prime}\right.$ Dell \& Jackson, 1998, pg 4). It is an umbrella term for a wide variety of interdependent and interlocking functions consisting of knowledge creation; knowledge valuation and metrics; knowledge mapping and indexing; knowledge transport, storage and distribution; and knowledge sharing (Coleman 1999). It formalize and access to experience, knowledge, and expertise that create new capabilities, enable superior performance, encourage innovation, and enhance customer value (Beckman 1999), by seeking synergistic combination of data and information processing capacity of information technologies, \& the creative and innovative capacity of human being (Malhotra-1998).

$\mathrm{KM}$ is the process of generating wealth from its intellectual or knowledge-based assets (Bukowitz and Williams-1999). And associated with "communications, capturing of best-yet practices and sharing for reuse what worked before" (Chatzkel-2000).There are generally two approaches in Knowledge Management: a centralized Knowledge Management and decision making approach, it hooks up all its suppliers and a 
decentralized approach and focus on shared knowledge among employees and business units (Yahya \& Goh, 2002).

Knowledge creation, validation, presentation, distribution and application are the five phases that allow an organization to learn, reflect, unlearn \& relearn usually considered essential for building, maintaining and replenishing of core competencies. KM provides an organization sufficient knowledge about both inside and outside of the company. To develop organizational knowledge base, individual knowledge is necessary. Knowledge creation is an emergent process (Lynn et al., 1996) that reflects the development of novel and useful ideas and solutions (Marakas, 1999, p. 440). This knowledge reconfigures and recombines the firm's existing piece of knowledge to increase the strength of research and development (R\&D) capabilities, scanning and monitoring external environments, and borrowing and employing external technologies (Bhatt, 2000b). Organization will need to shape and redefine interactions between its people, technology and techniques to manage knowledge. It found to carefully coordinate their social relations and technologies, those have been successful in obtaining long term benefits from knowledge management (Bhatt, 1998). According to Ernst \& Young, 56\% of executives believe changing people's behavior is one of the critical implementation problems in knowledge management (Glasser, 1998), as knowledge management force a company to redefine its traditional work procedures, power structures and technologies.

Traditionally a number of companies collaborated on the basis of transaction cost economies for implementation of knowledge management programs as it requires a change in organizational philosophy. KM helps a firm to attain its goal by improving its performance. $\mathrm{KM}$ is not only managing knowledge but also about changing entire business cultures and strategies of organizations to ones that value learning and sharing.

Requirement of Knowledge management is very important in this fast moving business world. It helps us to get more active and relevant knowledge for the firms in creating values. It is important to improve the organization performance and for that it is necessary to obtain the correct knowledge by the right people and at the right time. In a word, knowledge management helps the organization to innovate and be aggressive in the corporate world with its information, useful ideas and solutions to the problems.

In order to illuminate the debate on knowledge management, this paper analyses the relationship between human resource management (HRM) and KM. This will be done by, first, assessing whether knowledge management requires a particular human resource strategy and, second, by examining the basic HRM components of such strategies. Finally, it analyses the probable behavior effects of such strategies in the creation, distribution and use of knowledge.

\section{HUMAN RESOURCE MANAGEMENT}

HRM is the management which deals with the human as a resource. It is responsible for how people are treated in organizations. It brings people by helping them in performing their work, compensating them for their labors, and solving problems that arise into the organization. There are seven management functions of a human resources (HR) department, staffing, performance appraisals, compensation and benefits, training and development, employee and labor relations, safety and health, and human resource research.

HRM organize people toward the goal. It is a planned process by that an organization can control their employees and use them as a proper resource. HR is the system that a firm uses to know about their employees and evaluate them. The most important point is, under HRM, employees can develop themselves by training so that they can do the job properly. The core business of the HR function is to develop employees, including the selection and hiring of people, the training and developing of staff, evaluating their performance, rewarding them, and creating a culture of learning. HRM emphasizing the acquisition, organization and motivation of human resources (Armstrong 2000), as it is the management of the organizations employees (Scarpello and Ledvinka , 1988,p.4).

Understanding HRM depends highly on the perspective taken. HRM could be conceived as a resource- based employment relational ship or as a part of strategic management function (Beardwell and Holden 2001, pp.916), that reflect a shared responsibility among managers, employees, customers and suppliers for HRM. (Lengnick-Hall and Lengnick-Hall, 2003; Saint-Onge, 2001; Soliman and Spooner, 2000; Ulrich and Smallwood, 2003; Yahya and Goh, 2002).

Therefore, HRM can be defined as a specific combination of HR practices, work structures and processes that maximizes employee knowledge, skill, commitment, and flexibility. It composed of many interrelated parts that complement one another to reach the goals of an organization, large or small. We think HRM is the management which deals with the human as a resource. HRM could be conceived as traditional personal management and industrial relation as a source-based employment relationship or as a part of strategic managerial function. 


\section{THE IMPORTANCE OF KNOWLEDGE MANAGEMENT IN HUMAN CAPITAL MANAGEMENT}

This paper has concentrated on how HRM practices can encourage knowledge sharing and re-use. Here the main characteristics of the two ideal-typical KM strategies adopted by firms: effective and innovative has been described. More importantly, it also showed that management practices do not operate alone, divorced from the rest of the organization. Practices are, instead, interrelated and require a degree of compatibility and careful co-ordination. The general strategy of a firm and the HRM strategy, therefore, make up the general KM strategy.

Knowledge Management influences Human resource Management in a greater way. Today's HRM is KM-centered absolutely. KM and HRM are very much related with each other. Both people and knowledge are to be regarded as having special potential as scarce and idiosyncratic resources (e.g. Grant, 1991; Peteraf, 1993; Rumelt, 1991; Wernerfelt, 1984).

KM strategy is often classified by two patterns - explicit (information transferred in a systematic and standardized manner) or implicit pattern (information cannot be expressed in a standardized and systematic manner) (Hansen et al, 1999; Schulz and Jobe, 2001). Firms follow explicit pattern, provide limited opportunity among workers for interpersonal connections. On the other hand, employees communicate more extensively and share their implicit knowledge in the implicit pattern. Therefore, they use task force groups, emphasize organizational learning mechanisms and encourage employee interactions through appraisal and compensation systems. Another interesting thing is the effective KM strategy does stress a low-trust employment relationship (downsizing, outsourcing and peripheralisation).

A key point of KM is "contingent theories" (Chandler, 1962; Woodward, 1965; Lawrence and Lorsch, 1967; Galbraith, 1977). A concept of "contingent theories" is "fitness" (Pennings, 1987; Donaldson, 2001). It is used in strategic management. Perfect alignment between strategy and related factors enhances a company's performance (Woo and Cooper, 1981; Hambrick, 1984). A fit among HRM practices can improve employee performance and enhance company's core competitive advantage (Huselid, 1995; Huselid et al., 1997).

Knowledge Management is a very powerful factor in HRM today. KM related issues of HRM are used in the organizations continuously. KM- centered training actions within overall training planning, formal inclusion of $\mathrm{KM}$ duties in job design, productive knowledge sharing in performance appraisal and pay reviews etc. are being used in the organizations.

In the training session of the job, $\mathrm{KM}$ issues are heavily used to improve the performance of the employees in the organizations. In the job designing process, added KM duties show the job description precisely of the organizations.

In the performance appraisal of employees, productive knowledge sharing can enhance the sharpness of the overall system. It also uses in the pay scale reviews of the employees. HRM and KM responsibilities and duties together also reduce the contradictions of staff in HR-unit.

The implications of HRM factors for the management of knowledge are profound. Here such factors are linked with firm's strategy and represent the alignment of employee skills and behavior with the flow of knowledge that is needed in developing innovations. 'Codification' and 'personalization' are the two major strategy of KM that linked people flows and knowledge flows, found by a USA consultancy firms (Hansen et al. 1999). Codification, codify knowledge and store in database that is accessible by anyone and in personalization, knowledge is closely tied with the developer and shared with person-to person contacts (pg 107).

Another implication of KM in managing the human resource is in Knowledge-Intensive firms (KIFs), an organizational system which core competence is human and social capital. In KIFs most workers are intellectual and needed to be well educated and qualified to perform these works. As a result, the main goal of such firm is to provide qualified products or services. Here human capital focuses on two important issues-creative jobs and standardized work. So KM has a greater importance in HRM.

\section{Conclusion}

KM will mainly act as the idea generating process. This will be possible when employees will share their tacit knowledge with each other. Managers will have to ensure an environment of trust to make this possible. HRM will facilitate this idea generation and act as a catalyst for the implementation of these ideas generated through KM. So that it aligns with the corporate strategy. Learning and knowledge sharing can be a critical competitive advantage but will only work when the lessons learned will be implemented. KM cannot stand alone, it needs HRM to work collaboratively and in tandem with it and together if they fit they can create a. super-duper competitive advantage for the organization following the strategy and may make it the industry leader, ceteris paribus. So, Knowledge Management (KM) can be considered a key component of Human Resource Management based on its applications in the entire process that we learned during our research. In order to survive in the highly competitive environment, every organization has to make sure that they are using their core competencies, which for most organization is its knowledge, to sustain in the long run. Therefore they 
must be fully aware of its applications, the strategies involved in KM that help to shape the activities of HR along with a vivid idea of the relevant challenges in applying it.

\section{JOURNAL PAPERS}

\section{References}

[1]. Armstrong, M. (2000), "The name has changed but has the game remained the same", Employee Relations, Vol. 22 No. 6, pp. 576 93. Cited in, Svetlik Ivan \& Costea Eleni. 2007. "Introduction Connecting human resources management and knowledge management", International Journal of Manpower. Vol. 28, No. 3/4 , pp. 197-206.

[2]. Beardwell, I. and Holden, L. (2001), Human Resource Management: A Contemporary Approach, Pearson Education, London. Cited in, Svetlik Ivan \& Costea Eleni. 2007. "Introduction Connecting human resources management and knowledge management", International Journal of Manpower. Vol. 28, No. 3/4, pp. 197-206.

[3]. Beckman, T.J. (1999), “The current state of knowledge management”, in Liebowitz, J. (Ed.), Knowledge Management Handbook, CRC Press, Boca Raton, FL. Cited in, Gloet M \& Terziovski M. 2004. "Exploring the relationship between knowledge management practices and innovation performance", Journal of Manufacturing Technology Management. Vol. 15, No. 5, pp. 402409.

[4]. Bhatt, G. (1998), "Managing knowledge through people", Knowledge and Process Management: Journal of Business Transformation, Vol. 5 No. 3, pp. 165-71. Cited in, Bhatt, G. 2001. "Knowledge management in organizations: examining the interaction between technologies, techniques, and people", Journal of knowledge management. Vol. 5, No. 1, pp. 68-75.

[5]. Bhatt, G. (2000b), "Organizing knowledge in the knowledge development cycle", Journal of Knowledge Management: Journal of Business Transformation, Vol. 4 No. 1, pp. 15-26. Cited in, Bhatt, G. 2001. "Knowledge management in organizations: examining the interaction between technologies, techniques, and people", Journal of knowledge management. Vol. 5, No. 1, pp. 68-75.

[6]. Bhatt, G.D. (2001), "knowledge management in organizations: examining the interaction between technologies, techniques, and people", Journal of Knowledge Management, Vol. 5 No. 1, pp. 68-75. Cited in, Yahya Salleh \& Goh Wee. 2002. "Managing Human Resources toward”, Journal of Knowledge Management. Vol. 6, No. 5, pp. 457-468.

[7]. Chatzkel, J. (2000), "A conversation with Jim Botkin, President of Inter Class", Journal of Intellectual Capital, Vol, 1 No. 3, pp. 273- 86. Cited in, Yahya Salleh \& Goh Wee. 2002. "Managing Human Resources toward", Journal of Knowledge Management. Vol. 6, No. 5, pp. 457-468

[8]. Grant, R.M. (1991), “The resource-based theory of competitive advantage: implications for strategy formulation”, California Management Review, Vol. 33 No. 3, pp. 114-35. Cited in, Oltra Victor. 2005. "Knowledge management effectiveness factors: the role of HRM", Journal of Knowledge Management. Vol. 9, NO. 4, pp. 70-86.

[9]. Hambrick, D. (1984), "Taxonomic approaches to studying strategy: some conceptual and methodological issues", Journal of Management, Vol. 10, pp. 27-41. Cited in, Shih An Hsi \& Chiang Hwa Yun. 2005. "Strategy alignment between HRM, KM, and corporate development", International Journal of Manpower. Vol. 26, No. 6, pp. 582- 603.

[10]. Hansen, M.T. (1999), "The search transfer problem: the role of weak ties in sharing knowledge across organizational sub-units", Administrative Science Quarterly, No. 44, pp. 82-111. Cited in, Scarbrough Harry. 2003."Knowledge management, HRM and the innovation process", International Journal of Manpower. Vol. 24, No. 5, pp. 501-516.

[11]. Huselid, M.A. (1995), "The impact of human resource management practices on turnover, productivity, and corporate financial performance", Academy of Management Journal, Vol. 38 No. 3, pp. 635-72. Cited in, Oltra Victor.2005. "Knowledge management effectiveness factors: the role of HRM", Journal of Knowledge Management. Vol. 9, NO. 4, pp. 70-86.

[12]. Huselid, M.A., Jackson, S.E. and Schuler, R.S. (1997), "Technical and strategic human resource management effectiveness as determinants of firm performance", Academy of Management Journal, Vol. 40 No. 1, pp. 171-88. Cited in, Shih An Hsi \& Chiang Hwa Yun. 2005. "Strategy alignment between HRM, KM, and corporate development", International Journal of Manpower. Vol. 26, No. 6, pp. 582-603.

[13]. Lawrence and Lorsch (1967), Organization and Environment, Diversion of Research, Graduate School of Business Administration Harvard University Press, Boston, MA. Cited in, Shih An Hsi \& Chiang Hwa Yun. 2005. "Strategy alignment between HRM, KM, and corporate development", International Journal of Manpower. Vol. 26, No. 6, pp. 582-603.

[14]. Pennings, J.M. (1987), "Structural contingency theory: a multivariate test", Organization Studies, Vol. 8 No. 3, pp. 223-40. Cited in, Shih An Hsi \& Chiang Hwa Yun. 2005. "Strategy alignment between HRM, KM, and corporate development", International Journal of Manpower. Vol. 26, No. 6, pp. 582-603.

[15]. Peteraf, M.A. (1993), "The corner-stones of competitive advantage: a resource-based view", Strategic Management Journal, Vol. 14 No. 3, pp. 179-91. Cited in, Oltra Victor. 2005. "Knowledge management effectiveness factors: the role of HRM", Journal of Knowledge Management. Vol. 9, NO. 4, pp. 70-86.

[16]. Peteraf, M.A. (1993) 'The Cornerstones of Competitive Advantage: A Resource-based View', Strategic Management Journal, 14 179-91. Cited in, Haesli \&Boxall. 2005, 1955-1975. "When knowledge management meets HR strategy: an exploration of personalization retention and codification-recruitment configurations", Int. J. of Human Resource Management 16:11 November.

[17]. Rumelt, R.P. (1991), “How much does industry matter?”, Strategic Management Journal, Vol. 12 No. 3,pp. 167-85.Cited in, Oltra Victor. 2005. "Knowledge management effectiveness factors: the role of HRM", Journal of Knowledge Management. Vol. 9, NO 4, pp. 70-86.

[18]. Schulz, M. and Jobe, L.A. (2001), "Codification and tacitness as knowledge management strategies: an empirical exploration", Journal of High Technology Management Research, Vol. 12, pp. 139-65. Cited in, Shih An Hsi \& Chiang Hwa Yun. 2005. "Strategy alignment between HRM, KM, and corporate development", International Journal of Manpower. Vol. 26, No. 6, pp. 582 603

[19]. Soliman, F. and Spooner, K. (2000), "Strategies for implementing knowledge management: role of human resources management", Journal of Knowledge Management, Vol. 4 No. 4. Cited in, Thite Mohan. 2004. "Strategic positioning of HRM in knowledge-based organizations", The Learning Organization. Vol. 11, No. 1, pp. 28-44.

[20]. Soliman, F. and Spooner, K. (2000), "Strategies for implementing knowledge management: role of human resources management", Journal of Knowledge Management, Vol. 4 No. 4, pp. 337-45. Cited in, Oltra Victor. 2005. "Knowledge management effectiveness factors: the role of HRM", Journal of Knowledge Management. Vol. 9, NO. 4, pp. 70-86.

[21]. Soliman, F. and Spooner, K. (2000), "Strategies for implementing knowledge management: role of human resources management", Journal of Knowledge Management, Vol. 4 No. 4, pp. 337-45. Cited in, Gloet Marianne. 2006. "Knowledge management and the links to HRM- Developing leadership and management capabilities to support sustainability", Management Research News. Vol. 29, No. 7, pp. 402-413. 
[22]. Williams, A. (1999), Creativity, Invention and Innovation, Allen \& Unwin, Sydney. Cited in, Gloet Marianne \& Terziovski Mile' 2004. "Exploring the relationship between knowledge management practices and innovation performance", Journal of Manufacturing Technology Management. Vol. 15, No. 5, pp. 402-409.

[23]. Woo, C. and Cooper, A. (1981), "Strategies for effective low share business", StrategicManagement Journal, Vol. 2, pp. 301-18. Cited in, Shih An Hsi \& Chiang Hwa Yun. 2005. "Strategy alignment between HRM, KM, and corporate development", International Journal of Manpower. Vol. 26, No. 6, pp. 582-603

[24]. Yahya, S. and Goh, W.K. (2002), "Managing human resources toward achieving knowledge management", Journal of Knowledge Management, Vol. 6 No. 5, pp. 457-68. Cited in, Svetlik Ivan \& Costea Eleni. 2007. "Introduction Connecting human resources management and knowledge management”, International Journal of Manpower. Vol. 28, No. 3/4 , pp. 197-206.

[25]. Yahya, S. and Goh, W. (2002), "Managing human resources toward achieving knowledge management", Journal of Knowledge Management, Vol. 6 No. 5, pp. 457-68. Cited in, Gloet Marianne. 2006. "Knowledge management and the links to HRMDeveloping leadership and management capabilities to support sustainability", Management Research News. Vol. 29, No. 7, pp. 402-413.

[26]. Yahya, S. and Goh, W. (2002), "Managing human resources toward achieving knowledge management", Journal of Knowledge Management, Vol. 6 No. 5, pp. 457-68. Cited in, Shih An Hsi \& Chiang Hwa Yun. 2005. "Strategy alignment between HRM, KM,

\section{BOOKS} and corporate development", International Journal of Manpower. Vol. 26, No. 6, pp. 582-603.

[27]. Chandler, A.D. (1962), Strategy and Structure: Chapters in the History of America Industrial Enterprise, MIT Press, Cambridge, MA. Cited in, Shih An Hsi \& Chiang Hwa Yun. 2005. "Strategy alignment between HRM, KM, and corporate development", International Journal of Manpower. Vol. 26, No. 6, pp. 582-603

[28]. Coleman, D. (1999), “Groupware: collaboration and knowledge sharing”, in Liebowitz, J. (Ed.), Knowledge Management Handbook, CRC Press, Boca Raton, FL. Cited in, Gloet Marianne \& Terziovski Mile'. 2004. "Exploring the relationship between knowledge management practices and innovation performance", Journal of Manufacturing Technology Management. Vol. 15, No. 5, pp. 402-409.

[29]. Donaldson, L. (2001), The Contingency Theory of Organizations, Sage Publications, ThousandOaks, CA. Cited in, Shih An Hsi \& Chiang Hwa Yun. 2005. "Strategy alignment between HRM, KM, and corporate development", International Journal of Manpower. Vol. 26, No. 6, pp. 582-603.

[30]. Galbraith, J.R. (1977), Organization Design, Addison-Wesley, Reading, MA. Cited in, Shih An Hsi \& Chiang Hwa Yun. 2005. "Strategy alignment between HRM, KM, and corporate development", International Journal of Manpower. Vol. 26, No. 6, pp. 582603.

[31]. Marakas, G.M. (1999), Decision Support Systems in the Twenty-first Century, Prentice-Hall, Englewood Cliffs, NJ. Cited in, Bhatt, G. 2001. "Knowledge management in organizations: examining the interaction between technologies, techniques, and people", Journal of knowledge management. Vol. 5, No. 1, pp. 68-75.

[32]. Lengnick-Hall, M.L. and Lengnick-Hall, C.A. (2003), Human Resource Management in the Knowledge Economy, Berrett-Koehler, San Francisco, CA. Cited in, Thite Mohan. 2004. "Strategic positioning of HRM in knowledge-based organizations", The Learning Organization. Vol. 11, No. 1, pp. 28-44.

[33]. Lynn, G.S., Morone, J.G. and Paulson, A.S. (1996), “Marketing and discontinuous innovation: the probe and learn process", California Management Review, Vol. 38, pp. 8-37. Cited in, Bhatt, G. 2001. "Knowledge management in organizations: examining the interaction between technologies, techniques, and people", Journal of knowledge management. Vol. 5, No. 1, pp. 68-75.

[34]. Malhotra, Y. (1998), "Deciphering the knowledge management hype", Journal for Quality and Participation, Vol. 21 No. 4, pp. 5860. Cited in, Svetlik Ivan \& Costea Eleni. 2007. "Introduction Connecting human resources management and knowledge management", International Journal of Manpower. Vol. 28, No. 3/4 , pp. 197-206.

[35]. O’Dell, C. and Jackson, C. (1998), If Only We Know What we Know: The Transfer of Internal Knowledge and Best Practice, Free Press, New York, NY. Cited in, Svetlik Ivan \& Costea Eleni. 2007. "Introduction Connecting human resources management and knowledge management", International Journal of Manpower. Vol. 28, No. 3/4, pp. 197-206.

[36]. Scarpello, G.V. and Ledvinka, J. (1988), Personnel/Human Resource Management, PWS-Kent Publishing Company, Boston, MA Cited in, Svetlik Ivan \& Costea Eleni. 2007. "Introduction Connecting human resources management and knowledge management", International Journal of Manpower. Vol. 28, No. 3/4, pp. 197-206.

[37]. Woodward,J. (1965), Industrial Organization: Theory and Practice, Oxford University Press, London. Cited in, Shih An Hsi \& Chiang Hwa Yun. 2005. "Strategy alignment between HRM, KM, and corporate development", International Journal of Manpower. Vol. 26, No. 6, pp. 582-603.

[38]. Ulrich, D. and Smallwood, N. (2003), "What's next for the people function? a missing link for delivering value', in Effron, M., Gandossy, R. and Goldsmith, M. (Eds), Human Resources in the 21st Century,Wiley, Hoboken, NJ. Cited in, Gloet Marianne. 2006. "Knowledge management and the links to HRM- Developing leadership and management capabilities to support sustainability", Management Research News. Vol. 29, No. 7, pp. 402-413.

\section{WEBSITES}

[39]. Saint-Onge, H. (2001), Strategic Capabilities: Shaping Knowledge Management within the Knowledge-Driven Enterprise, available at: www.knowinc.com/saintonge/library/strategic.htm (accessed 17 February 2003). Cited in, Gloet Marianne. 2006. "Knowledge management and the links to HRM- Developing leadership and management capabilities to support sustainability", Management Research News. Vol. 29, No. 7, pp. 402-413. 